\title{
Cuando despertó, la histeria todavía estaba allí. Globus hystericus en la hipermodernidad y relato de una psicoterapia.
}

Upon waking, hysteria was still there. Globus hystericus in hypermodernity and a psychotherapy case report.

\author{
Javier Ramos García ${ }^{a}$. \\ ${ }^{a}$ Psicólogo Clínico. Unidad de Psicoterapias Hospital 12 de Octubre. AGCPSM Hospital 12 de Octubre, \\ Madrid, España.
}

Correspondencia: Javier Ramos García (jramospsic@hotmail.com)

Recibido: 31/07/2013; aceptado: 26/12/2013

\begin{abstract}
RESUMEN: La histeria, inmortal e irreductible, habituada a declararse una y otra vez en rebeldía cuando intenta ser ninguneada y expulsada de las nosografías contemporáneas, se ha mostrado siempre fugaz y proteica, capaz de evolucionar en sus expresiones clínicas y de adaptarse con brillantez a los cambiantes escenarios culturales con que se ha topado a lo largo de la historia. Así, resulta poco probable que la modernidad líquida en la que ha triunfado la fibromialgia asista a espectaculares ataques "à la Sapêtrière". Y, sin embargo, siguen apareciendo en ocasiones llamativos y deliciosamente anticuados cuadros como el bolo histérico que presentamos y que suscita el abordaje psicoterapéutico del que se da cuenta a continuación.

PALABRAS CLAVE: Histeria, conversión, globus hystericus, psicoterapia.
\end{abstract}

\begin{abstract}
Hysteria, immortal and elusive, has since forever tended to insurrection against the stablished order, specially when contemporary nosographies have tried to ignore and throw it out. Shooting and protean, it has shown the ability to evolve and adapt itself to changing cultural settings throughout history. Thus, it is strange that in liquid modernity, in which fibromyalgia reigns, severe attacks "à la Salpêtrière" happen. Nevertheless, delicious oldfashioned syndromes like globus hystericus show up in clinical settings, and they provoke psychotherapeutic approaches like the one described bellow.

KEY WORDS: Hysteria, conversion, globus hystericus, psychotherapy.
\end{abstract}

Histeria fin de siglo (XIX).

Lucien Israël (1), uno de los más delicados y dedicados estudiosos de la histeria del pasado siglo, recomendaba acudir a las extraordinarias descripciones del Diccionario Enciclopédico de Ciencias Médicas inaugurado por Dechambre en 1864 para apreciar en toda su riqueza la semiología histérica. En la entrada "Hystérie", redactada por Grasset en 1899 (2), el autor subraya cómo "la fugacidad de los síntomas coloca a la histeria en un lugar aparte, aun dentro de las demás neurosis"; se extiende al detallar las características de una histeria común (hysteria minor) que anticipa la histeria de angustia de Freud (3); y nos conduce al apartado dedicado a los "fenómenos fijos" o "síntomas al margen de los ataques" para dibujar la 
noción de globus hystericus, la sensación de bolo, tan frecuente como fenómeno histérico que Briquet decía haberla encontrado en 370 de 400 casos estudiados. Bolo que tomaba muchas veces la forma de "sensación de que se ha tragado un cuerpo extraño y que ha quedado parado en la faringe, que no se puede hacer que suba ni que baje". Y que podía acompañarse, también en el tubo digestivo, de "convulsiones parciales como los vómitos", algunas veces "incoercibles".

Centro de Salud Mental de Carabanchel, Madrid, en la segunda década del siglo $X X I$.

Atiendo por primera vez a E en los primeros días del año 2012. Con 47 años, casada, con dos hijos cercanos a la veintena, se presenta como una mujer atractiva, de aspecto muy cuidado, perfecta en su apariencia física (1), en su peinado, en su vestido, y también en su discurso, sereno y preciso: contenido en lo emocional (aunque a veces las lágrimas se deslicen silenciosas por su rostro) y claro en lo narrativo, evocador de la resignada belle indifférence. Su relato, con una prosodia tenue, desgrana las circunstancias en que, unos meses antes, durante las vacaciones de Semana Santa, hace su aparición el síntoma que se constituye en su motivo de consulta: la sensación muy vívida y desagradable de "tener en la garganta algo muy parecido a una pelota de tenis". Estaba en Londres, con su marido y sus hijos, en un viaje "que a ella no le apetecía haber hecho". Allí, una noche, su marido y su hijo varón, de 23 años, se fueron a ver un partido de fútbol, mientras que la paciente y su hija, de 18, optaron por salir a cenar. Recuerda que ya estaba inquieta porque no le gustaba el barrio en el que estaba el restaurante. Era muy oscuro y le daba miedo. La cena le sentó mal, y amaneció con la referida molestia en la garganta. A partir de ahí, con una sostenida dificultad para tragar y con constantes problemas digestivos, inicia un tormentoso peregrinaje médico que pasa por un momento álgido de angustia durante el verano -cuando teme padecer un cáncer u otra enfermedad grave- y que culmina con la derivación a Salud Mental desde la hipótesis de que sus síntomas puedan explicarse como una histeria de conversión. Hipótesis que no resulta descabellada a una paciente que, atónita, se desespera con el hecho de que los médicos no sean capaces de ver nada a pesar de la infinidad de pruebas realizadas y que sufre hasta el punto de fantasear con que un cirujano avezado pudiese introducir algún utensilio quirúrgico para extraerle "esa especie de bola de pelo". 
NOTAS CLÍNICAS

\section{Itinerario clínico.}

El primer contacto de la paciente con Salud Mental tiene lugar en 2000, en la urgencia de un hospital general, al que llega con una crisis de angustia que se acompaña de componentes agorafóbicos y sensación de desorientación espacial y temporal (en la exploración no acierta a decir cuántos años tiene o dónde vive). En esos momentos la paciente narra lo siguiente: Unos diez años antes, su madre le revela que no es su madre biológica, sino que la había adoptado siendo pequeña, y le pide que mantenga en secreto esta información de cara a otros familiares o amigos, alegando que nunca se sabe cómo puede reaccionar la gente ante revelaciones de este tipo. La paciente hizo una suerte de negación de este relato, poniéndolo en duda, pese a lo cual sufrió varios episodios de angustia que remitieron espontáneamente. No volvió a pensar en ello, hasta el año 2000, cuando una serie de trámites familiares conllevan que solicite en un Registro su partida de nacimiento. Al ver plasmado en un documento oficial la evidencia de la falsedad de la que había creído siempre que era su filiación, su equilibrio mental se quiebra y se sumerge en una crisis de angustia. "Sus padres eran otros, su lugar de nacimiento era otro; ni siquiera su nombre era el mismo". Empezó a vomitar de una forma incontenible, hasta el punto de requerir un ingreso hospitalario. Se desencadena después la clínica ansiosa, en forma de crisis, iniciando a partir de ahí tratamiento psiquiátrico y psicológico (en clave conductual) "que la ayudó mucho" en un principio, pese a que le disgustaba verse "etiquetada" por una terapeuta que "se centraba en exceso en las técnicas de relajación y muy poco en otras cosas importantes de su vida". "Estuvo años tomando tranquilizantes" que sólo fue dejando cuando "se vio ya lo suficientemente fuerte", hacia 2006... Pese a ello, los episodios de pánico reaparecen con prontitud y facilidad, sin que exista una posibilidad clara de delimitar los precipitantes. Retoma el contacto con Salud Mental en 2008, reinstaurándose una pauta farmacológica que irá variando sin cesar -como consecuencia de la dificultad para acceder a una mejoría real- y reabriéndose un abordaje psicoterapéutico que tampoco resulta ya tan exitoso como antaño. Los síntomas de ansiedad, no obstante, parecen ir remitiendo, hasta que irrumpe durante las referidas vacaciones familiares "esa sensación de tenaza en la garganta", esa "bola de pelo" que le impide tragar y condiciona toda su vida.

\section{Retrato subjetivo de su biografía.}

Hija única, relata una estupenda infancia, muy feliz a pesar de la trágica muerte de su padre cuando ella tenía 3 años. Aquejada con frecuencia de amigdalitis, 
los médicos recomendaban a la familia pasar los períodos estivales en la sierra. Un verano, tras un día dedicado al baño en una presa, su padre, del que tiene muchos recuerdos y al que define como "firme" pero también "risueño y tranquilo", sufre una trombosis. Recuerda con horror el viaje hasta Madrid en ambulancia, el aullido de las sirenas que durante años no va a soportar escuchar. Se traslada a una ciudad del Sur peninsular con su madre, que es descrita como "la mejor persona que ha conocido", cariñosa y generosa, capaz de hacer sentir a la paciente la persona más importante de su vida, "con autoridad y mano de seda". Se establecen en casa de una tía de la paciente durante tres años que E recuerda, a pesar de la orfandad, como maravillosos; por el clima relacional reinante y por la excelente sintonía vivida con sus primas, a las que aún hoy, pese a los años y la distancia, sigue muy apegada. Y también pese a que todos (excepto ella misma) sabían que era adoptada. Regresan a Madrid cuando E tiene 6 años. Su madre trabajaba como peluquera, y la desbordaban los encargos, "vivía esclavizada peinando". Ésa es la razón por la que la paciente, estudiosa y brillante, renuncia a la Universidad para hacer un curso de secretariado. "Había que hacer algo rápido, que permitiese encontrar un trabajo y ayudar en casa". A los 15 años conoce al que será su marido. Le resultó interesante: "callado, sensato, tranquilo, ubicado, metódico". Al año, se aburrió, rompió con él, pasó una temporada "muy loca", saliendo mucho. Después quiso volver a la tranquilidad, y retomó la relación con él. Ella trabajaba mucho, en una firma de artículos de lujo, desarrollando una actividad profesional intensa y gratificante que no sólo le va a permitir "retirar" a su madre de su penoso empleo, sino disfrutar de las múltiples fiestas y eventos sociales que formaban parte de su actividad laboral. Un mundo que termina por abandonar al casarse, en una dolorosa renuncia que narra impasible y que asume con el fin de evitar los constantes conflictos que se generaban con su pareja, que fue siempre un hombre muy celoso.

Se casa con 23 años, y su matrimonio resultará frustrante e insatisfactorio ya desde el viaje de bodas. "Hubo mucho sexo, pero también mucha frialdad e indiferencia, y muy poco cariño".

La pareja se instala en la casa de la madre de la paciente, cuya salud era muy precaria ya en ese momento, y con la que el marido de E chocaba constantemente. El ambiente era irrespirable y la paciente, profundamente decepcionada por el trato que recibía en su matrimonio, decide romper a los 6 meses de la boda. Pone las maletas de su pareja en la puerta totalmente decidida a la ruptura. Al descubrir poco tiempo después que está embarazada, resuelve reanudar la relación desde el planteamiento irrenunciable de no querer ofrecer a su hijo una vida sin padre, como la que a ella le tocó vivir.

Con su madre enferma, con la llegada de los hijos, con la renuncia a su carrera profesional y a su vocación artística y creativa, su existencia y su identidad se despliegan y se agotan casi en exclusiva desde el lugar de cuidadora, lo que le 
NOTAS CLÍNICAS

permite canalizar un carácter afectivo y cariñoso que -como termina por reconocer con amargura- ha perdido con el paso de los años y las decepciones: "se ha cansado de dar y de no recibir".

Digerir lo que no se puede tragar: Pensando significaciones y liberando emociones desde una postura mentalizante (4-5).

Si bien al acercarnos a la histeria nos acompaña siempre la idea freudiana del poder curativo de un proceso en el que ciertos contenidos mentales devienen conscientes al tiempo que tiene lugar una abreacción emocional (6), y si no resulta concebible renunciar a la idea clásica de que el síntoma puede disolverse al ser dotado de un sentido que procede de la escucha del terapeuta (7), nuestra forma de abordar el sufrimiento conversivo en las desbordadas consultas del siglo XXI se ve impregnada también por las líneas trazadas por autores como Fiorini (8) en la segunda mitad del siglo XX, y por los desarrollos psicoterapéuticos contemporáneos, en los que la de la Teoría del Apego (9) se articula con conceptos tales como el de capacidad de mentalización (10) para enriquecer la idea de que el soma recibe y transmite casi siempre lo que no puede expresarse con palabras (11) y para consolidar la concepción de psicoterapia como proceso mentalizante. Es decir, para pensar la psicoterapia como un trabajo en pos de una conexión creciente con la propia subjetividad; de potenciación de la posibilidad de pensar acerca de los sentimientos; de re-conversión de los síntomas -que se presentan como cuerpos extraños- en elementos propios de lo psicológico y que pueden ser por tanto integrados en el caudal saludable del funcionamiento mental.

Bowlby (12) insiste en que la primera tarea del terapeuta es la de proveer al paciente de una base segura desde la cual éste pueda explorar los múltiples aspectos desdichados y dolorosos de su vida, pasados y presentes. Y ése es nuestro propósito inicial a fin de que E pueda asomarse por encima de la pantalla del síntoma para acercarse a los duelos acumulados a lo largo de su vida; para que pueda atreverse a investigar datos velados de su historia; para que pueda afrontar la frustración con la que vive su relación conyugal y su renuncia a aspectos existenciales muy relevantes para ella. Así a lo largo de 18 sesiones que tienen lugar cada tres semanas aproximadamente y que se extienden a lo largo de poco más de un año.

Indefectiblemente, cada sesión se inicia con una pormenorizada descripción de su clínica digestiva, de su curso, de lo infructuoso de los remedios farmacológicos que se le pautan, de los muy molestos efectos secundarios que tales remedios le generan. Y de la desesperación que todo esto le supone. Requiere de mucha paciencia y tenacidad y de un sostenido esfuerzo sacar a la paciente del formato de 
consulta psiquiátrica, traer a la paciente a su vida, a sus relaciones, a sus recuerdos, a su mundo psíquico. Restar protagonismo al organismo enfermo para que se imponga en la escena el sujeto hablante (15). Y es así como puede hablar de su historia, reescrita tantas veces.

Es así como puede, repentinamente, a través de fotos y de conversaciones familiares, tomar conciencia de que su padre (insólitamente parecido en lo físico al hijo de la paciente) sí era su padre biológico. Y recomponer entonces un rompecabezas en el que su madre adoptiva aceptó por alguna razón asumirla como hija cuando su marido había tenido a esa niña con otra mujer. ¿Es entonces ella el fruto de una traición? ¿Cómo es posible que su madre adoptiva la amase tanto cuando ella encarnaba el engaño de su marido?

Es así también como puede acceder al desencanto que atraviesa su propio matrimonio. "Ha tenido todo lo material: perfumes, vestidos, coches, tarjetas del El Corte Inglés. Pero muchas carencias, mucho desdén, mucho desamor, mucha soledad. Vive en esa contradicción desde hace muchos años, cansada ya de reclamar". Durante el curso, en la pareja cada uno hace su vida. Él dedicado a su trabajo, y ella a sus cursos, a sus actividades. Pero las vacaciones de verano son terribles. Frías... Hace tres años fue la última vez que habló con franqueza con su marido, le imploró un cambio de actitud, ante lo cual él se mostró distante, negador y desconcertado. Ella terminó llorando sola en un banco en la calle.

Súbitamente recuerda un hecho relevante acaecido poco antes del viaje a Londres que sirve de escenario a la irrupción del síntoma. Una de sus primas, a la que le une una estrecha relación y que es una figura muy importante para ella, se va casar, finalmente, con su pareja de siempre. Para la paciente es muy importante acudir. De hecho su prima le pide que sea la madrina. Y va. Sola. Una vez más. Su marido se excusa en el trabajo que todo lo llena, cuestionando además, desde la descalificación, el hecho de que E asuma ese nivel de implicación cuando su prima no es realmente su prima, ya que no es de su misma sangre. Tras la boda, a los 15 días, el marido de esta prima fallece repentinamente de un infarto. Desmadejada, la paciente va, también sola, al funeral y al entierro. Llora amargamente al hablar de todo esto, revelando (con un toque inevitablemente seductor) que en ningún otro sitio puede hablar de estas cosas. Sale descompuesta.

En la siguiente cita me comunica el llamativo desbloqueo que tiene lugar poco después de nuestro último y movilizador encuentro. Se produce una potente liberación emocional, y el síntoma desaparece casi por completo, aunque las molestias, atenuadas, retornan algunos días después.

Sin embargo, el sometimiento a su propia exigencia de perfección, de insatisfacción, de alienación en el deseo del otro, queda socavado en el inicio de un camino que se inicia y que no parece ya tener retorno; un trayecto que la conduce a contactar con un creciente deseo de libertad y rebelión (plasmado en bellos sue- 
ños que la paciente trae a consulta); de dejar de tragar, de digerir la posibilidad de negarse a ese constante complacer al otro. Incluso si ese otro es el terapeuta, como demuestra al declinar la posibilidad de seguirme en el traslado al que nos vemos obligados cuando el CSM se reubica en una nueva dirección lejana a su domicilio. La paciente se va de alta. La bola de pelo se ha disuelto. La histeria, como estructura fundamental sigue ahí, pero en el caso de E, el síntoma cede; el globus hystericus se retira.

\section{BIBLIOGRAFÍA}

(1) Israël L. La jouissance de l'hystérique; 1974. (Trad. Cast. El goce de la histérica. Buenos Aires: Argonauta; 1979).

(2) Grasset J. "Hystérie". En Dechambre A y Lereboullet L (Dirs.). Dictionnaire Encyclopédique des Sciences Médicales. Paris: Asselin et Houzeau/G. Masson; 1889. Recogido en VV. AA. La histeria antes de Freud. Madrid: Edición de los Alienistas del Pisuerga; 2010.

(3) Laplanche J, Pontalis J-B. Vocabulaire de la psychanalyse; 1968. (Trad. Cast. Diccionario de psicoanálisis. Barcelona: Labor; 1971).

(4) Fiorini HJ. Estructuras y abordajes en psicoterapias psicoanalíticas. Buenos Aires: Nueva Visión; 1993.

(5) Lanza Castelli G. Mentalización y agencia del paciente en el proceso psicoterapéutico. Aperturas Psicoanalíticas 2009; 33 (www.aperturas.org.).

(6) Freud S. Estudios sobre la histeria; 1895. En Obras completas. Madrid: Biblioteca Nueva; 1973.

(7) Nasio JD. L'hystérie ou l'enfant magnifique de la psychanalyse; 1990. (Trad. Cast. El dolor de la histeria. Buenos Aires: Paidós; 1991).

(8) Fiorini HJ. Estructuras y abordajes en psicoterapias psicoanalíticas. Buenos Aires: Nueva Visión; 1993.

(9) Marrone M. La Teoría del Apego. Un enfoque actual. Madrid: Psimática; 2001.

(10) Allen JG, Fonagy P, Bateman A. Mentalizing in Clinical Practice. Arlington: American Psychiatric Publishing; 2008.

(11) Wallin DJ. Attachment in Psychotherapy. New York: Guilford Press; 2007.

(12) Bowlby J. A Secure Base: Parent-Child Attachment and Healthy Human Development. New York: Basic Books; 1988.

(13) Israël L. L’hystérique, le sexe et le médecin; 1976, pág. 157. (Trad. Cast. La histeria, el sexo y el médico. Barcelona: Toray-Masson; 1979). 